\title{
Moda: Cultura Material, Modos de VestiR e de Se Apresentar
}

Tal como comunicamos aos leitores da revista Cadernos de Arte e Antropologia, o nosso objetivo inicial era organizar um dossiê que contribuísse, numa perspectiva etnográfica, com novas reflexões para o campo de estudos sobre a moda e o vestir. Propusemos centrar os olhares sobre a produção (o desenhar, o fazer, mas também o apresentar, o escrever sobre); os objetos e as técnicas (as qualidades materiais e formais dos objetos, as técnicas de construção, os modos de fazer, as técnicas de vestir e usar); as práticas (as maneiras de vestir, mas também as maneiras de comprar, de vender, de dar, de guardar, de descartar, de mostrar); e as representações (as imagens, os discursos, os sentidos).

Contemplando diversos caminhos a pavimentar a reflexão sobre a moda, as contribuições foram generosas, especialmente no que se refere às abordagens que exploravam as práticas do vestir. A seleção nos facultou, porém, a observação de que ainda há múltiplas possibilidades para investigar o tema da moda-vestuário, pois o fazer, ação que se relaciona com as técnicas e as possibilidades de produzir moda, ainda nos pareceu pouco explorado nas pesquisas.

Escolhemos, ao fim, construir o número deste dossiê amparadas em dois eixos fundamentais. O primeiro deles, a produção, e o segundo, a fruição como etapa do processo de consumo, conduzindo-nos aos modos de vestir - em especial no que se refere à performance.

De acordo com Eicher (2000), a antropologia se tornou um campo de observação privilegiado para estudar a moda. Em seu texto The Anthropology of Dress, a autora enumera contribuições que a antropologia ofereceu a este campo de estudos. A primeira delas, o holismo que, segundo Eicher, nos força a olhar o vestir dentro de um espectro mais amplo que engloba, inclusive, sistemas de parentesco e economia política. Outra contribuição foi a ideia de cultura e diversidade cultural, que, para a autora, enriquecem as análises sobre os significados do vestir. A terceira contribuição, o trabalho de campo que se tornou definitivo para investigar a roupa e

1 Faculdade de Design de Moda do SENAI-CETIQT, Centro de Tecnologia da Indústria Química e Têxtil. Contato: solange_riva@hotmail.com.

2 Faculdade de Ciências Sociais e Humanas, Universidade Nova de Lisboa e Centro em Rede de Investigação em Antropologia (CRIA-FCSH). Contato: fsilvano@fcsh.unl.pt. 
o comportamento por trás das escolhas. Por fim, aos olhos de Eicher, o envolvimento feminino neste campo investigativo é notório. Talvez isso justifique a predominância feminina nas respostas que recebemos para compor este número.

A perspectiva etnográfica, prática de pesquisa tributária da antropologia, foi o ponto de contato entre os trabalhos. Isso não obliterou o diálogo com outros campos de conhecimento, como a filosofia, a história, a sociologia e a semiologia. Ao contrário. Sobre esse aspecto o texto inicial, intitulado Encontros entre moda e antropologia: Inícios, debates e perspectivas, assinado pelas organizadoras do dossiê, abre as reflexões trazendo para o leitor o estado da arte da moda no pensamento social ocidental, seja como objeto de estudo, seja como prática exemplar para se pensar as sociedades. O objetivo do texto foi situar o leitor, revelando a dimensão que os estudos sobre moda tomaram para as ciências sociais - desde o pensamento econômico, neste campo representado por Adam Smith e Thortein Veblen, passando pela proposta fundadora de Georg Simmel até os mais recentes projetos como a perspectiva da cultura material, especialmente abordada por Daniel Miller e Susanne Küschler.

Ao longo dos anos, o fenômeno da moda vem interessando cada vez mais aos pesquisadores. E é aqui que vemos como perspectivas para o futuro o alargamento do enfoque das pesquisas incluindo as diversas formas de se produzir moda, tanto no sentido material (indústria 4.0, perspectiva sustentável, nostalgias das relações artesanais de produção) quanto da revitalização do conceito, abordando aspectos que vão da criação, ao desfile ou vitrine. É notável, além disso, que os debates surgidos ao longo do século $\mathrm{XX}$ abriram múltiplas possibilidades no campo da moda, inclusive, gerando novas formas de trabalho, como, por exemplo, o personal stylist, o personal shopper, o instagramer, o figurinista, o profissional de visual merchandising, entre outras.

Sobre a produção de vestuário, há um enorme caminho a ser percorrido e Schneider nos ajuda a percorrê-lo. Em seu trabalho de 1987, The Anthropology of Cloth, a autora elenca importantes estudos etnográficos a destacarem o fazer e os significados dos quais as roupas eram investidas no momento de sua feitura, especialmente em sociedades tradicionais.

Do outro lado, sobre o consumo, dentre os estudos que abordam o perfil do consumidor moderno, Colin Campbell (2004), retomando o trabalho de Don Slater (2002), analisa este tipo específico, e é quem problematiza o papel deste diante da produção. Se Slater explora o contraponto entre um consumidor idiotizado pelos recursos midiáticos e mercadológicos e uma racionalidade que entende a liberdade de consumo como liberdade civil, Campbell concebe uma ideia de consumidor moderno criativo - o consumidor artesão. Este seria alguém que, para usar as palavras de Douglas e Isherwood em seu hoje clássico The world of goods, ${ }^{3}$ se valeria da faculdade humana de criar, expressando-se através do uso peculiar de elementos da produção de origem industrial. Esta concepção nos leva a pensar que o consumidor moderno de moda dispõe de inúmeros recursos para criar o seu projeto imagético diário.

Entre a produção industrial e artesanal é onde encontramos a segunda contribuição da nossa coletânea. No que se refere à industrialização, as ideias marxistas desenvolvidas no século XIX, se tornaram centrais para pensar a transição entre um modelo baseado na produção artesanal e as relações de produção envolvidas no modelo capitalista. Em 1904, Max Weber em sua obra Die Protestantische Ethik und der Geits des Kapitalismus interpretou a consolida-

$3 \quad$ Publicado pela primeira vez em 1979. 
ção do capitalismo como consequencia da ética protestante. Esta teria alimentado o "espírito capitalista" numa trajetória coincidente. Boltanski e Chiapello (1999), leitores dessa dinâmica capitalista pós manifestações de maio de 1968 na França, argumentam que, gradativamente, um novo espírito capitalista assoma nas sociedades modernas, absorvendo as reivindicações por justiça social e se reinventando ao incorporar em suas práticas as críticas, silenciadas, na visão dos autores, já a partir da década de 1970. Uma dessas reivindicações parece ser a estética, já que no campo do design, o modo industrial de produção, num primeiro momento, pasteurizou as formas. Mais recentemente, Gilles Lipovetsky e Jean Serroy (2015) se esmeraram em explicar o boom estético que vem dominando a produção. Dizem os autores:

Os imperativos de estilo, de beleza, do espetáculo adquiriram tamanha importância nos mercados de consumo, transformaram a tal ponto a elaboração dos objetos e dos serviços (...) que se torna difícil não reconhecer o advento de um verdadeiro 'modo de produção estético' que hoje alcançou a maioridade. (Lipovetsky e Serroy 2015: 40)

É neste cenário que Mariana Silva problematiza, em seu texto A Arte de Fazer Sapatos: Modos de Fazer e de Apresentar na Indústria de Calçado Portuguesa, o fazer e as relações de produção numa fábrica de sapatos portuguesa. A leitura de uma "produção estética", ao fim, leva ao resgate de modos tradicionais de elaboração e fabricação, incorporando à força de trabalho das fábricas, os profissionais que dominam a arte de produzir objetos com as próprias mãos. Esta, por sinal, uma prática descrita por Richard Sennett em sua obra The Craftman (2008) sobre o artífice, como uma relação entre as mãos e a cabeça na transformação da matéria, tendo na repetição, não uma cena exemplar de alienação, mas um movimento em direção ao aprimoramento das técnicas. A chamada indústria 4.0, que se autoproclama arauto de uma nova revolução industrial, demonstra esforço de conjugar um modelo de produção capitalista com o cuidado estético e a exclusividade da produção artesanal. Ou seja, uma produção que procura atrelar ao discurso relacionado com o profissional envolvido na produção, qualificações do artesão: o bem-fazer, a exclusividade, o esmero.

Uma fala que a autora destaca de sua experiência etnográfica, com base na percepção de uma informante, parece expor contradições observadas neste modo de produzir. Mesmo algumas "falhas" no produto podem ser "toleradas" em nome da percepção de que são produtos artesanalmente confeccionados. Isso aponta para uma ordem de valor. A “imperfeição”, portanto, denuncia um trabalho manual, não padronizado. Este seria o contraponto a uma lógica fordista, quando a perspectiva de produção em massa encontra na padronização a chave para abrir as possibilidades de horizontalização dos acessos. "Pode-se escolher um Ford de qualquer cor, desde que seja preto" - o mote fordista verbalizado por seu idealizador, Henry Ford, no início do século $\mathrm{XX}$, reafirma que os valores relacionados com o volume da produção se sobrepõem à valorização estética e de exclusividade. A questão que se coloca no texto de Silva está na percepção do embaçamento da classificação do trabalhador, cujo esforço de produzir algo com um quê de exclusividade (mesmo numa lógica de produção industrial), conclui a autora, se esvai no poderoso mercado da moda.

Da fábrica portuguesa, vamos encontrar o sertão brasileiro, resgatando a memória da técnica dos bordados. Thais Brito vai buscar em Ingold a inspiração para discorrer sobre as linhas e a arte dos bordados em seu texto Narrativas e Tecidos Bordados.

A leitura desta pesquisadora facilmente nos remete ao trabalho de Ingold intitulado The life of lines. Assim ele inicia este livro: "lançados à maré da história, temos que nos agarrar às 
coisas, pois elas nos compensarão das correntes que nos levam ao esquecimento"4 (Ingold 2015: 3). A trajetória das coisas pode estar inscrita no ato de bordar, numa metáfora que envolve pontos, linhas e bordados com o desenrolar do novelo da história. Não por acaso, ela cita Ingold por sua antropologia comparativa da linha. Afinal, como ela mesma afirma: "linhas nos interessam"!

A observação de um pedaço de tecido, fragmento de um turbante indiano exposto no museu Victoria \& Albert, faz com que Brito se surpreenda com a semelhança do bordado daquela peça com os pontos que conhece das bordadeiras do Caicó. Como poderia um bordado num turbante indiano do século XVIII se assemelhar ao bordado nordestino no Brasil? Em seu trabalho de campo identifica entre as bordadeiras nordestinas a narrativa da herança que vem da Ilha da Madeira, e assim, a autora vai desfiando a trama que relaciona o trabalho das artesãs de Caicó com as da Ilha da Madeira e o bordado do turbante. Em The life of things, originalmente publicado em 1986, Arjun Appadurai afirma que as coisas seguem um percurso, e seus significados estão, sobretudo, inscritos nessa trajetória que perpassa diferentes regimes de valor. Para as bordadeiras nordestinas, o valor está inscrito exatamente nesta trajetória, ou seja, na narrativa da herança madeirense. Por isso, ao relacionar os bordados com o conceito de mercadoria, a autora mais se aproxima da visão de Appadurai do que Marx. Afinal, para o primeiro autor, a ideia de mercadoria está inserida num processo cultural que constroi a percepção de valor às coisas - neste caso, o dos bordados, novamente, o valor está na narrativa.

O dossiê fotográfico publicado neste número da revista integra-se também na temática da produção, mas neste caso num contexto de trabalho em que as práticas artesanais se cruzam com as lógicas criativas do design de moda contemporâneo. É dedicado aos desenhos de moda do designer português Filipe Faísca e surge acompanhado por uma pequena entrevista centrada na questão do papel do desenho no processo de produção de roupa do criador.

Diferente de outros designers, na maioria das suas coleções Faísca começa por trabalhar numa relação direta com a matéria - numa lógica de empatia que se insere nas dinâmicas estudadas por Tim Ingold (2015) e por Susanne Kuchler (2009) - utilizando o desenho sobretudo para se relacionar com as peças de roupas já existentes. Uma vez produzidas, desenha-as numa espécie de segundo processo de apropriação corporal e simbólica. A multiplicidade dos trajetos das técnicas e dos valores, tratada no texto de Brito, revela-se também na utilização, feita pelo designer, de bordados da Madeira, numa parceria com o "Instituto do vinho, do bordado e do artesanato da Madeira”, que resultou da vontade institucional de revalorizar os mesmos colocando-os no campo da criação de moda. Os bordados surgem, nas duas coleções que resultaram da referida associação, trabalhados de dois modos distintos: numa lógica de ready made, deslocando peças antigas, como toalhas de mesa ou naperons, ${ }^{5}$ para o terreno do vestir, ou numa lógica de invenção de novos bordados que partiu de uma pesquisa prévia sobre desenhos científicos de flores e de insetos.

A fruição das roupas está na segunda parte do nosso dossiê, tratando a moda e o vestuário numa perspectiva de consumo, mais especificamente, como elementos da nossa expressão identitária e como performance.

4 Tradução das autoras.

5 Pano bordado ou de renda, geralmente usado para adornar centros de mesa e outros móveis. 
Mary Douglas foi quem, na segunda metade da década de 1970, declarou que a antropologia poderia dar conta da complexidade envolvida nas diversas práticas de consumo. Até então havia, de um lado, nas ciências sociais, o estudo baseado na economia da dávida, explorado por Marcel Mauss em seu clássico Essai sur le don, de 1925, e de outro, nas ciências econômicas, as práticas racionais e utilitaristas gerenciando escolhas cotidianas. Escrito em 1979, em parceria com o economista Baron Isherwood, The world of goods ${ }^{6} \mathrm{faz}$, antes de tudo, exatamente uma crítica à visão utilitária do consumo. A crítica se estende a Thorstein Veblen, pois se este autor avança para além do pensamento econômico, Douglas e Isherwood avaliam que sua visão do consumo ainda é simplista, ao atribuir à emulação um papel chave nos processos de escolhas. $O$ Mundo dos Bens posiciona, pela primeira vez, os bens, seus valores sociais e categorias culturais, no debate sobre consumo, destacando especialmente suas propriedades classificatórias. É nesse sentido que podemos enquadrar a moda como um critério de escolha dos itens relacionados com o vestuário. Ou seja, como podemos pensar a moda como agente classificador ou um conjunto de bens que podem, nas palavras de Douglas e Isherwood, servir como cercas ou como pontes nas interações sociais? A eficácia das propriedades comunicativas da moda-vestuário poderá ser medida pelo acolhimento ou não dos indivíduos em seus projetos de pertença.

Assim, a questão da identidade parece ser o primeiro aspecto a ser percebido quando enveredamos pelo campo da moda. Campbell (2006) ${ }^{7}$ sugere que o consumo, mais do que expressar ou construir, elucida identidades. Assim, o diálogo entre o self e a roupa é, antes de tudo, algo íntimo e estreito. Nesta linha de trabalho, podemos incluir os textos de Marion Braizaz e Isabel Wittmann, respectivamente, trazendo a moda-vestuário como elemento que opera questões relacionadas com a identidade de gênero entre mulheres e entre transgêneros.

Em Femininity and Fashion: How Women Experience Gender Role Through their Dressing Practices, texto que abre a segunda parte do nosso dossiê, Braizaz recorda que as mulheres são, desde cedo, encorajadas a cuidarem da própria imagem e a se preocuparem com os olhares e o escrutínio público. Essa prática pode ter sua gênese relacionada com a valorização social da mulher no período renascentista, como aponta Vigarello (2006) ao mencionar que a beleza se torna um atributo feminino fundamental para sua existência social desde então. Para Braizaz, esta preocupação com a própria imagem é a razão pela qual elas (as mulheres) desenvolvem reflexividade acerca de sua aparência, incluindo aqui o processo de escolha envolvido nas práticas do vestir, que se converte em estratégia de construção identitária relacionada com um ideal de feminilidade.

Vale a pena nos empenharmos numa rápida digressão sobre a noção de reflexividade, especialmente tratada no diálogo entre Ulrich Belk e Anthony Giddens. Este último autor, em seu livro Modernity and self-identity, elabora a ideia do self como projeto reflexivo na modernidade. Seria um modelo de conduta onde o indivíduo presta atenção ao que ocorre a sua volta e procura relacionar seu próprio comportamento àqueles eventos (Giddens, 2002). É neste sentido que a reflexividade, mencionada por Braizaz, se dá entre as mulheres que entrevistou em provável confronto entre a sua própria aparência e aquela que se ventilou no mundo ocidental como idealização de beleza fortemente sedimentada pelo mundo da moda - é precisamente esta a

\footnotetext{
6 Em tradução para o português: O Mundo dos Bens.

7 O título do artigo é: Eu compro, logo sei que existo: as bases metafísicas do consumo moderno (do original: I shop, therefore I know that I am: the metaphysical basis of modern consumerism), publicado no Brasil na coletânea Consumo, cultura e identidade, organizado por Lívia Barbosa e Colin Campbell em 2006.
} 
observação de Marwick (2009), para quem a mídia especializada reforçou a relação entre a ideia de moda e de beleza.

Diante disso, as interlocutoras de Braizaz desenvolvem suas próprias estratégias para lidar com este "reflexo", para usar um termo de Belk ${ }^{8}$. Retomando Giddens (2002), são estratégias que se tornam âncoras cognitivas na construção de uma segurança ontológica.

Com um trabalho de campo realizado em Paris com homens e mulheres, a autora analisa discursos, e propõe quatro tipos ideais de estratégias que identificou entre as mulheres. São eles: successful femininity - hegemonic interiorization; ironical femininity - hegemonic complicity; femininity by default - to undergo hegemony e fleeting femininity. As mulheres classificadas no primeiro grupo (successful femininity), para a autora, ao se olharem no espelho, se encontram com a "imagem dos sonhos". Esse "capital", qual seja, o da aparência desejada, proporciona a esta mulher, uma relação de aprovação entre o seu papel estético feminino e o seu Eu, o que a faz conduzir suas escolhas cotidianas com certo nível de segurança. No grupo que a autora denominou ironical femininity, estão aquelas mulheres que, embora desejem desafiar padrões de beleza vigentes, temem adotar uma postura excessivamente crítica, colocando em jogo a sua credibilidade. O terceiro grupo, femininity by default, inclui mulheres que fazem dos padrões estéticos hegemônicos seu referencial, algo constitutivo da sua identidade feminina. Não atendendo a esses padrões, percebem que precisam tomar o controle de suas vidas. Por fim, Braizaz analisa o grupo que denominou fleeting femininity. Mais instáveis, as mulheres deste grupo optam por uma postura mais ousada em suas escolhas e terminam por ser afetadas pelas consequências que esse comportamento acarreta.

Ainda sobre o tema da identidade de gênero, Isabel Wittmann nos apresenta o texto $A$ Roupa Expressa a Identidade: Moda enquanto Tecnologia de Gênero na Experiência Transgênero. Quando Margareth Mead publicou sobre sua pesquisa de campo realizada na Papua Nova Guiné em 1935 - Sex and temperament in three primiteve societies - a antropóloga, discípula de Franz Boas, desencadeou questões que permeiam até hoje os estudos sobre gênero. Observando as famílias Tchambuli, Arapesh e Mundugumor, Mead relatou padrões de comportamento (e temperamento), que envolviam relações entre homens e mulheres diferentes do que conhecia em seu próprio processo de socialização. Desconectar a ideia de gênero e sexualidade, desde então, se tornou um desafio. Mais recentemente, a historiadora Joan Scott (1998) afirmou que a ideia de gênero passa pelo discurso sobre a diferença de sexos, mas remete, também, a instituições, estruturas, práticas cotidianas e rituais. Se, num primeiro momento, os estudos sobre gênero se concentravam nas pesquisas realizadas com enfoque no feminismo, o campo vem se ampliando incluindo novas definições, e encontram na teoria Queer uma perspectiva epistemológica que procura dar conta de atribuições de gênero classificadas como minorias. Judith Butler (1990) é um dos nomes mais importantes deste quadro teórico, tendo-se dedicado ao tema incansavelmente, e inspirado o ativismo de grupos minoritários. Em sua obra, ela chama a atenção para a limitação da liberdade de escolha individual no que se refere ao gênero, mas admite que é possível o empenho em novas leituras das normas de comportamento socialmente padronizadas. É neste sentido que a moda pode ser um dispositivo a contribuir para a performance de indivíduos transgêneros, como propõe Wittmann. A autora, através de pesquisa pela internet, aborda este delicado universo.

8 Para Belk, reflexão difere de reflexo. Este último conceito pressupõe uma repercussão não planejada, um desconhecimento - diferentemente da "reflexão" que parte do conhecimento. Ver Domingues (2002). 
É digno de nota que recentemente foi divulgado pelo site Hypeness um documento redigido em Nova York pela Comissão dos Direitos Humanos, dando conta do reconhecimento de 31 diferentes classificações de gênero, ${ }^{9}$ produto de uma análise combinatória que extrapola três traços fundamentais do self: afetos-sexualidade-relação com o próprio corpo. A proposta da autora do artigo que nesta oportunidade apresentamos, observando a performatividade de pessoas com identidade trangênero, ou seja, que não se identificam com o gênero que lhes foi atribuído ao nascer, é questionar a própria noção de gênero no âmbito da moda.

A moda como tecnologia de gênero transmite valores relacionados com os gêneros feminino e masculino, ou seja, reproduz significados já conhecidos e referenciados no modelo binário. Para a autora, aí reside a chave para repensarmos e desafiarmos este esquema de reconhecimento em direção a uma neutralidade.

O próximo texto apresentado é de Mariana Batista dos Santos, e se intitula $A$ Elegância como Forma de Ser e Agir: Moda, Cultura Material e Performance na 'Sapelogie' Congolesa. Santos trata roupa e identidade num contexto específico pós-colonial. Johnathan Friedman (1994), em seu livro Cultural Identity \& Global Process, que reforça a crítica à teoria utilitária aplicada ao comportamento de consumo, faz sua análise no seio da sociedade congolesa, em Brazzaville com os adeptos da SAPE - Societé des Ambianceurs et Personnes Elegantes. Os sapeurs, membros da SAPE, são congoleses que, vestindo-se com critérios de elegância europeus, se destacam da população geral e ganham um caráter politizado na medida em que suas roupas, luxuosas e mimetizando o estilo francês (colonizador) de vestir, mostram sua oposição ao regime militar da etnia Mbochi imposto a partir de 1968 no país. Em outras palavras, os Sapeurs reproduzem, ao afrontar um regime que bloqueia localmente as referências do colonizador, um modo estereotipado do vestir elegante ocidental. Uma ideia de elegância que, diga-se de passagem, no ocidente, foi forjada no dandismo - especialmente personificada na figura de Beau Brummel. ${ }^{10}$

Friedman, analisando a SAPE, destaca o caráter distintivo embutido nesse processo de consumo, o que ele chama de economia política da elegância e que é mantida hoje, graças a constantes viagens a Paris, e de lá, de volta à Brazzaville, percurso que é conhecido entre eles como l'aventure (aventura). É aqui que se encaixa o trabalho de Santos. A autora, que fez sua etnografia na cidade de Paris, interage com os sapeurs em sua incursão pela cidade a fim de adquirirem os ternos e outras peças que os distinguirão em seu país. Há entre os sapeurs uma hierarquia relacionada com a origem de suas roupas. No nível mais baixo da escala sapeur, estão aqueles que as confeccionam junto aos alfaiates locais. Em seguida, estão aqueles cujas roupas são adquiridas das coleções prêt-à-porter de grandes estilistas, e os que compram cópias da alta costura. No topo da hierarquia estão os sapeurs que adquirem suas roupas em Paris com os grandes estilistas, ou seja, os que empreendem a aventura, o que faz desse fluxo transnacional, de pessoas e coisas, um elemento privilegiado de observação da autora. Ulf Hannerz (1997), em trabalho que busca elucidar metáforas relacionadas com a antropologia transnacional, trata a ideia de "fluxo" como algo contínuo, diferente de "fronteira" que define bem quem "está den-

9 Ver https://www.hypeness.com.br/2016/06/nova-york-agora-reconhece-31-diferentes-tipos-de-genero/

10 Apesar de ser reconhecida a gênese do dandismo na Inglaterra, na figura de George Brummel, a literatura francesa, especificamente através de Baudelaire, Balzac e D'Aurevilly, vai contribuir para disseminar o estilo de vida relacionado ao dandismo e o modo dândi de se vestir. Ver: Baudelaire, Charles; Balzac, Honoré de; D’Aurevilly, Barbey. 2012. Manual do Dândi: a vida com estilo. Belo Horizonte: Ed. Autêntica. Ver também: Balzac, Honoré de. 2016. Tratado da vida elegante: ensaios sobre a moda e a mesa. São Paulo: Companhia das Letras. (Primeira edição 1830). 
tro" e quem "está fora". Santos destaca que, embora muitos congoleses adeptos da sapeologie tenham a intenção de se estabelecer em Paris, é exatamente no fluxo, na aventure, que o reconhecimento da identidade sapeur chega ao apogeu, pois é no retorno que o rito de passagem que marca a ascensão para uma categoria mais prestigiosa de sapeur, se concretiza.

O texto que fecha o nosso dossiê é parte do estudo de Mylene Mizrahi sobre a indumentária funk no Rio de Janeiro, e se intitula O Funk, a Roupa e o Corpo: Caminhos para uma Abordagem Antropológica da Moda.

Antes dela, o antropólogo carioca Hermano Vianna (1988) foi quem estudou os bailes funks pela primeira vez. Inicialmente organizado nos subúrbios cariocas e frequentado pela população de baixa renda, o funk se expandiu para outros domínios, mesmo sendo, ainda, estigmatizado por boa parte da população do Rio de Janeiro. No rastro de noticiários que repercutiam espisódios de violência nos bailes, cresceu o preconceito contra o funk e suas festas, gerando, inclusive, mais recentemente (2017), um projeto de lei que previa a criminalização do funk. O projeto foi rejeitado e o funk se tornou parte da cultura carioca.

Foi neste conturbado contexto que Mizrahi realizou seu trabalho etnográfico. No artigo aqui apresentado, a autora rememora o momento em que, da arquibancada de uma festa funk, observa o universo indumentário local, tratando, como ela mesma diz, a moda como registro da materialidade. Se a análise da roupa masculina atendeu aos critérios de relação com o corpo, entre as meninas, Mizrahi precisou recorrer aos trabalhos de Miller e Gell para desvendar a concepção imagética daquela indumentária. Assim, ela conclui que as moças e suas roupas constituem, concordando com Miller, o próprio sujeito e sua ação. Ou seja, roupa, corpo e performance se encontram amalgamados constituindo um todo que se produz no esquema da festa.

\section{REFERÊNCIAS BIBLIOGRÁFICAS}

Appadurai, Arjun. 2008. A vida social das coisas. As mercadorias sob uma perspectiva cultural. Niterói: EdUFF. Primeira publicação, The social life of things: commodities in cutural perspective em 1986.

Balzac, Honoré de. 2016. Tratado da vida elegante: ensaios sobre a moda e a mesa. São Paulo: Companhia das Letras. Primeira publicação, Traité de la vie élegante: essai sur la mode et la table em 1830.

Baudelaire, Charles; Balzac, Honoré de; D’Aurevilly. 2012. Manual do dândi. A vida com estilo. Belo Horizonte: Autêntica Editora.

Beck, Ulrich; Giddens, Anthony; Lash, Scott. 1997. Modernização reflexiva: politica, tradição e estética na ordem social moderna. São Paulo: Editora da Universidade Estadual Paulista.

Boltanski, Luc; Chiapello, Ève. 1999. Le nouvel esprit du capitalisme. Paris: Gallimard.

Butler, Judith. 1990. Gender trouble - feminism and the suversion of identity. London: Routledge. Campbell, Colin. 2004. O consumidor artesão: cultura, artesania e consumo em uma sociedade pós-moderna. Em Antropolítica: Revista Contemporânea de Antropologia e Ciência Política. - n.17. Niterói: EdUFF.

Campbell, Colin. 2006. Eu compro, logo sei que existo: as bases metafísicas do consumo moderno. Em Barbosa, Lívia; Campbell, Colin. Consumo, cultura e identidade. Rio de Janeiro: FGV. 
Domingues, José Maurício. 2002. Reflexividade, individualismo e modernidade. Em Revista Brasileira de Ciências Sociais. Vol. 17, n. 49. P.p.: 55-70.

Douglas, Mary ; Isherwood, Baron. 1979. The world of goods. Towards an anthropology of consumption. London: Allen Lane Ed..

Eicher, Joanne B.. 2000. The Anthropology of dress. Em Dress, vol. 27, Maney Publishing; Costume Society of America.

Friedman, Jonathan. 1994. Cultural Identity \& Global Process. London: Sage Publications.

Giddens, Anthony. 2002. Modernidade e identidade. Rio de Janeiro: Jorge Zahar Ed.

Hannerz, Ulf. 1997. Fluxos, fronteiras, híbridos: palavras-chave da antropologia transnacional. Em Revista Mana 3 (1). Rio de Janeiro. P.p.: 7-39.

Ingold, Tim. 2015. The life of lines. New York: Routledge.

Hannerz, Ulf. 1997. Fluxos, fronteiras, híbridos: palavras-chave da antropologia transnacional. In.: Revista Mana 3 (1). 7-39.

Küchler, Susanne e Daniel Miller (editors). 2005. Clothing as material culture. Oxford: Berg.

Küchler, Susanne e Graeme Were. 2009. "Empathie avec la matière - Comment repenser la nature de l'action technique". Pp.190-211 em Techniques Eீ Culture. n52-53.

Lipovetsky, Gilles e Jean Serroy. 2015. A estetização do mundo: viver na era do capitalismo artista. São Paulo: Companhia das Letras.

Marwick, Arthur. 2009. Uma história da beleza humana. São Paulo: Senac.

Marx, Karl. 1867. Das Kapital. Kritik der politischen Ökonomie. Hamburg: Verlag von Otto.

Mauss, Marcel.1968. Essai sur le don. Forme et raison de l'échange dans les sociétés archaïques. Paris: PUF - Colletion Quadrige. Primeira publicação em 1925.

Mead, Margareth. 1977. Sex and temperament in three primitive societies. London: Routledge. First published in 1935.

Schneider, Jane. 1987. The anthropology of cloth. In Annual Review of Anthropology, vol. 16. P.p.: 409-448.

Scott, Joan. 1998. La citoyenne paradoxale: les féministes françaises et les droits de l'homme. Paris: Ed. Albin Michel.

Sennett, Richard. 2008. The craftsman. New Haven: Yale University Press.

Slater, Don. 2002. Cultura do consumo e modernidade. São Paulo: Nobel.

Veblen, Thorstein. 1980. A teoria da classe ociosa. São Paulo: Abril Cultural (Os Pensadores). Primeira publicação, The theory of leisure class, em 1899.

Vianna, Hemano.1988. O mundo Funk Carioca. Rio de Janeiro: Jorge Zahar Editor. Vigarello, Georges. 2006. A bistoria da beleza. O corpo e a arte de se embelezar, do Renascimento aos dias de hoje. Rio de Janeiro: Ediouro.

Weber, Max. A ética protestante e o espirito do capitalismo. São Paulo: Ed. Guazelli, 14a. Edição. Primeira publicação, Die Protestantische Ethik und der Geist des Kapitalismus, em 19041905. 